\title{
Causa básica da morte por causas externas: validação dos dados oficiais em Recife, Pernambuco, Brasil
}

\author{
Maria Dilma de A. Barros, ${ }^{1}$ Ricardo Ximenes ${ }^{2}$ \\ e Maria Luiza C. de Lima ${ }^{3}$
}

RESUMO Objetivo. Validar a causa básica da morte nas declarações de óbito por causas externas de menores de 20 anos residentes em Recife (PE), Brasil, em 1995.

Métodos. O estudo foi dividido em duas etapas: codificação e validação. Nas duas etapas, os dados oficiais sobre causas de morte foram comparados aos dados obtidos na pesquisa. Para tanto, as declarações de óbito foram agrupadas em 5 categorias principais e subdivididas em 14 categorias secundarias de causa da morte; foram, também, comparadas individualmente até o quarto dígito da classificação suplementar para causas de morte da nona revisão da Classificação Internacional de Doenças. Analisou-se a concordância entre os dados oficiais e os dados do estudo através do índice kappa e da sensibilidade. A categorização da pesquisa foi tomada como padrão.

Resultados. Na etapa de codificação, para o total das causas externas, o percentual global de concordância variou de 94\% (cinco categorias) para 92\% (14 categorias), caindo, por fim, para $81 \%$ (comparação até o quarto dígito). Na etapa de validação, o percentual global de concordância variou de $94 \%$ (cinco categorias) para 91\% (14 categorias) e 73\% (comparação até o quarto dígito).

Conclusões. Os resultados revelam que, para obtenção de dados mais fidedignos, é necessário que as declarações de óbito sejam preenchidas pelo Instituto de Medicina Legal dentro de padrões recomendados; por outro lado, as guias de remoção de cadáveres precisam ser melhor preenchidas em hospitais e delegacias quando do encaminhamento ao Instituto. É fundamental gerar e divulgar dados mais precisos para que a sociedade conheça melhor o seu padrão de violência.

Palavras-chave Certificado de óbito, causa da morte, violência, medicina legal.

1 Universidade de Pernambuco, Faculdade de Ciências Médicas, Departamento de Medicina Social. Correspondência e pedidos de separatas devem ser enviados a esta autora no seguinte endereço: Rua Arnóbio Marques 310, Santo Amaro, CEP 50100-130, Recife, PE, Brasil. E-mail: dilma@elogica. com.br

2 Universidade Federal de Pernambuco, Hospital das Clínicas, Departamento de Medicina Tropical, Recife (PE), Brasil.

3 Universidade de Pernambuco, Faculdade de Ciências Médicas, Coordenação de Pós-Graduação, Recife (PE), Brasil.
As dificuldades referentes à classificação das causas básicas de óbito estão presentes em todo o mundo (1-6). No Brasil, são citadas em grande parte dos estudos sobre causas externas (7-16) e outras causas (17-19).

Os dados de mortalidade por causas externas no Brasil são registrados nos sistemas de informações sobre mortalidade (SIM) dos municípios e têm como fontes oficiais as secretarias de segurança pública e as secretarias municipais e estaduais de saúde. Esses são órgãos fortemente burocratizados, com atribuições, objetivos e funções sociais distintas, onde a tarefa de informar está deslocada de sua função social, não sendo, portanto, considerada importante. Assim, já na geração dos dados há uma considerável perda, 
resultante da não definição das responsabilidades que cabem a cada uma dessas instituições.

Além disso, a falta de consenso interfere na produção dos dados. Para os peritos do Instituto de Medicina Legal (IML), esclarecer as circunstâncias em que ocorreu a morte significa determinar a causa jurídica do óbito — podendo esta ser utilizada para fins judiciais; enquanto isso, para os serviços de saúde, esclarecer essas circunstâncias significa conhecer o início do processo que levou ao óbito, o ponto de intervenção por excelência (20). Assim, é possível que na declaração de óbito (DO) os peritos do IML registrem como causa básica de morte a natureza da lesão - por exemplo, lesão perfurocontundente de tórax e assinalem o tipo de violência como ignorado; dessa forma, esse óbito seria classificado no grupo de outras formas de violência de intencionalidade ignorada. No entanto, se a guia de encaminhamento do hospital ou delegacia informar que se trata de homicídio, os pesquisadores e serviços de saúde que investigam a causa básica classificariam o mesmo óbito como homicídio.

As estatísticas de mortalidade são apresentadas segundo a causa básica de morte, e esta é definida, no caso das causas externas, como as circunstâncias do acidente ou violência que produziram a lesão fatal (21). Quando existem indícios de acidente ou violência, há a determinação legal de que os óbitos sejam atestados pelos médicos do IML, após a necropsia (10). Quando, apesar dos indícios, os médicos do IML não conseguem determinar a intencionalidade da lesão, os óbitos são classificados no grupo de lesões sobre as quais se ignora se foram acidental ou intencionalmente infligidas (21). O percentual de óbitos nessa categoria em relação ao total de óbitos por causas externas é um indicador de qualidade das informações, isto é: quanto maior o número de óbitos por lesão sobre a qual se ignora se foi acidental ou intencional, pior a qualidade das informações (22).

Entre 1980 e 1989, Recife apresentou valores altos para os óbitos por lesões de origem ignorada (entre $14 \%$ e $33 \%$ ). A partir de 1990, esses números caíram, atingindo, em 1994, 7\% $(23,24)$. Isso se deveu ao fato de que, a partir de 1990, a Secretaria Municipal de Saúde da Prefeitura da Cidade do Recife (SMS/PCR) passou a complementar os dados nas DO com o tipo de violência ignorado, utilizando, para tanto, as informações contidas nas guias preenchidas nos hospitais ou delegacias quando do encaminhamento dos cadáveres ao IML (25).

$\mathrm{O}$ objetivo do presente estudo foi avaliar o SIM no tocante às causas externas, em função da ausência, na literatura consultada, de estudos envolvendo validação da causa básica nas mortes por causas externas em Recife, e da possibilidade de trazer subsídios ao setor público para melhorar a coleta de dados e embasar a crítica aos dados do SIM - favorecendo, pois, a produção de dados mais fidedignos que permitam à sociedade conhecer melhor o seu processo de violência e assumir as decisões mais adequadas para enfrentá-lo. Para tanto, foram validadas as causas básicas de óbitos por causas externas em menores de 20 anos residentes em Recife (PE), Brasil, em 1995.

\section{MATERIAIS E MÉTODOS}

O estudo foi dividido em duas etapas: codificação e validação junto ao Instituto de Medicina Legal. Foram codificados 292 óbitos e validados 284 óbitos por causas externas de crianças e adolescentes residentes em Recife em 1995 e que foram objeto de necropsia pelo IML.

\section{Fonte e coleta de dados}

Foram utilizados os dados do SIM da SMS/PCR. Também foram utilizadas as DO originais, para cópias xerográficas e consultas.

A partir de uma lista com os números das DO por causas externas, foram identificados e selecionados 292 casos de menores de 20 anos. Um perito em classificação da causa básica de morte usou as cópias xerográficas das DO selecionadas para codificar as causas básicas dos óbitos. Procurou-se garantir que o perito, ao codificar os óbitos, contasse com as mesmas informações usadas pelos codificadores na SMS/ PCR. Assim, foram eliminados das DO os códigos de causa básica, o tipo de violência e o tipo de acidente inseridos pelos técnicos da SMS/PCR. Portanto, o perito dispunha apenas das informações sobre o tipo de violência e o tipo de acidente assinaladas pelo legista.

$\mathrm{Na}$ etapa de codificação, o perito classificou os óbitos segundo a classificação suplementar de causas externas da nona revisão da Classificação Internacional de Doenças (CID-9). A classificação suplementar utiliza quatro dígitos para classificar as causas de morte. O quarto dígito (de 0 a 9) foi acrescido às categorias de 3 algarismos para maior detalhamento das mesmas. Como teve em mãos as mesmas informações que os técnicos da SMS de Recife, as diferenças nessa etapa foram basicamente de codificação.

Em etapa posterior, de validação, o perito investigou a causa básica dos mesmos óbitos no IML, utilizando um formulário onde constavam apenas os números de identificação das $\mathrm{DO}$, a idade e o sexo dos indivíduos; o perito não teve acesso à codificação feita pelo serviço de saúde em qualquer dos momentos do estudo. Após definir as causas básicas, fez a codificação segundo a CID-9. Portanto, nesse momento o perito não trabalhou com as informações que o legista transferiu para as DO, mas sim com aquelas existentes no IML (laudo de necropsia e guias de encaminhamento de cadáveres de hospitais e delegacias).

Oito dos óbitos do estudo não foram atestados pelo IML; assim, o número de DO para a etapa de validação foi de 284 .

\section{Plano de descrição e análise dos dados}

Os dados da pesquisa da causa básica de morte por causas externas, tanto na sua etapa de codificação, antes da investigação no IML, como 
nos resultados desse processo de validação junto ao IML, foram inicialmente distribuídos em cinco categorias: acidentes de trânsito, outros acidentes, suicídios, homicídios e outras formas de violência. A seguir, os cinco grupos foram subdivididos em 14 categorias de causas externas: atropelamentos, outros acidentes de trânsito, quedas acidentais, acidentes causados por fogo e chamas, afogamentos acidentais, acidentes por corrente elétrica, demais acidentes, suicídios por armas de fogo, outras formas de suicídio, homicídios por armas de fogo, homicídios por instrumentos cortantes e penetrantes, outras formas de homicídio, afogamentos com intencionalidade ignorada e outras formas de violência com intencionalidade ignorada. Isso foi feito já que se procurava ter a visão da concordância em grupos menos abrangentes. A subdivisão se deu segundo interesse da pesquisa e mantendo a simetria necessária ao cálculo do índice kappa (26). Finalmente, os óbitos foram individualmente codificados utilizando os quatro dígitos identificadores da causa básica.

Os dados oficiais sobre a causa básica da morte, elaborados da mesma forma, foram cotejados com os da pesquisa antes e depois da investigação no IML. A primeira etapa de comparação objetivou observar divergências relativas à codificação. Na segunda fase, as concordâncias e discordâncias observadas refletem diferenças resultantes dos processos de classificação e investigação de causa básica.

Como medida de concordância foi utilizado o índice kappa de Cohen, adequado às variáveis qualitativas. Esse índice mede o grau de concordância além daquele que seria esperado pelo papel do acaso, e foi usado para verificar a concordância entre a classificação de dois observadores. No presente estudo, optou-se por trabalhar com múltiplas categorias, calculando o índice kappa geral, mas seria também possível considerar cada uma delas isoladamente em contraposição às demais $(26,27)$. Vale lembrar, no entanto, que tal procedimento levaria ao aumento do valor do índice kappa esti- mado, uma vez que a sua magnitude depende do número de categorias estudadas (26). Por não se estar trabalhando com categorias ordenadas, não se utilizou o índice kappa ponderado que atribui diferentes pesos a níveis diversos de discordância $(26,27)$. Para testar a hipótese nula, calculou-se o intervalo de confiança de 95\% (IC95\%) em torno do valor do índice kappa. Similarmente, através do intervalo de confiança, seria possível testar a hipótese de que um determinado valor do índice kappa não difere de um outro valor pré-especificado. Ressalte-se, porém, que somente seria adequado comparar o valor do índice kappa de diferentes estudos quando as prevalências por categoria não diferissem, uma vez que a variação da proporção de indivíduos por categoria implica uma variação na freqüência esperada e, conseqüentemente, no valor do índice kappa (26).

Como medidas de concordância foram utilizados, além do índice kappa simples, o percentual de concordância global e a sensibilidade expressa em valores percentuais $(26,28,29)$. Partiuse da pressuposição de que os dados da pesquisa eram mais fidedignos do que os dados oficiais e, portanto, foram tomados como padrão para o cálculo da sensibilidade, a exemplo de vários estudos $(2,17)$. Os cálculos foram elaborados com o programa Statistical Package for the Social Sciences (SPSS).

\section{RESULTADOS}

\section{Comparação entre dados oficiais e dados da pesquisa na etapa de codificação}

A partir da análise dos óbitos classificados em cinco grupos específicos de causas externas, observou-se que, dos 26 codificados na categoria outras formas de violência pela pesquisa, oito (31\%) foram classificados como outros acidentes e quatro (15\%) como homicídios nos dados oficiais (tabela 1). A sensibilidade da codificação de causa básica dos dados oficiais em relação ao padrão (pesquisa) aparece na tabela 2. No caso dos suicídios, o valor abaixo de $90 \%$ pode ter sofrido influência do pequeno número de casos. A concordância para o agrupamento segundo o índice kappa foi de 0,916 (IC95\% = 0,876-0,955), considerada ótima. O percentual global de concordância foi $95 \%$.

A distribuição das 292 DO em 14 categorias (tabela 3) revelou mais sete discordâncias entre os dados da pesquisa e os dados oficiais; contudo, a sensibilidade permaneceu alta, exceto para homicídios por instrumentos cortantes e para as lesões de intencionalidade ignorada. O índice kappa foi de 0,895 (IC95\% = 0,856-0,934) e o percentual global de concordância foi de $92 \%$. Apesar de ter-se encontrado uma classificação considerada ótima para o índice kappa, tanto para os agrupamentos com

TABELA 1. Causas básicas de óbito por causas externas conforme dados oficiais e dados da pesquisa na etapa da codificação dos dados, Recife (PE), Brasil, 1995a

\begin{tabular}{|c|c|c|c|c|c|c|}
\hline \multirow[b]{2}{*}{$\begin{array}{l}\text { Dados da } \\
\text { pesquisa }\end{array}$} & \multicolumn{6}{|c|}{ Dados oficiais } \\
\hline & $\begin{array}{c}\text { Acidentes } \\
\text { de } \\
\text { trânsito }\end{array}$ & $\begin{array}{l}\text { Outros } \\
\text { acidentes }\end{array}$ & Suicídios & Homicídios & $\begin{array}{c}\text { Outras } \\
\text { formas de } \\
\text { violência }\end{array}$ & Total \\
\hline \multicolumn{7}{|l|}{ Acidentes } \\
\hline Outros acidentes & 1 & 54 & 0 & 0 & 1 & 56 \\
\hline Suicídios & 0 & 0 & 8 & 0 & 1 & 9 \\
\hline Homicídios & 0 & 0 & 0 & 149 & 0 & 149 \\
\hline \multicolumn{7}{|l|}{ Outras formas de } \\
\hline violência & 0 & 8 & 0 & 4 & 14 & 26 \\
\hline Total & 52 & 62 & 8 & 154 & 16 & 292 \\
\hline
\end{tabular}

a Óbitos de menores de 20 anos classificados antes da consulta ao Instituto de Medicina Legal, somente com base nas informações disponíveis na Secretaria Municipal de Saúde de Recife. 
TABELA 2. Distribuição em cinco categorias e concordância entre os dados oficiais e os dados da pesquisa na etapa de codificação da causa básica de morte, Recife (PE), Brasil, $1995^{\mathrm{a}}$

\begin{tabular}{lcccc}
\hline & \multicolumn{4}{c}{ Número de ocorrências } \\
\cline { 2 - 5 } Causa básica & Pesquisa & Oficiais & Concordantes & Sensibilidade (\%) \\
\hline Acidentes & & & & \\
de trânsito & 52 & 52 & 51 & 98 \\
Outros acidentes & 56 & 62 & 54 & 89 \\
$\quad$ Suicídios & 9 & 8 & 8 & 100 \\
Homicídios & 149 & 154 & 149 & 54 \\
$\begin{array}{l}\text { Outras formas de } \\
\quad \text { violência }\end{array}$ & 26 & 16 & 14 & - \\
$\quad$ Total & 292 & 292 & 276 & \\
a Óbitos de menores de 20 anos classificados antes da consulta ao Instituto de Medicina Legal, somente com base nas infor- \\
mações disponíveis na Secretaria Municipal de Saúde do Recife.
\end{tabular}

cinco como com 14 categorias, observou-se a diminuição da concordância com agrupamentos menos abrangentes, isto é, naqueles com 14 categorias.

Considerando a codificação até o quarto dígito, foram identificadas mais 33 divergências, sendo 10 em nível do terceiro e 23 em nível do quarto dígito. Devido à dificuldade de apresentar os dados dessa comparação, optamos por distribuir os dados nas mesmas 14 categorias do agrupamento anterior, para fins de apresentação em tabela (tabela 3). Verificou-se que todos os óbitos codificados como atropelamentos pelo padrão foram classificados da mesma forma nos dados oficiais. Esse nível de análise mostrou, ainda, que tanto a pesquisa quanto os dados oficiais classificaram mais de $25 \%$ dos acidentes de trânsito na categoria sem outra especificação.

As maiores diferenças encontradas entre a análise até o quarto dígito e a análise dos agrupamentos se referem aos acidentes que não os de trânsito e às outras formas de violência com intencionalidade ignorada. Entre os primeiros destacaram-se os afogamentos, onde a sensibilidade chegou a $18 \%$. Para os homicídios, verificaram-se mais três discordâncias não apontadas nos agrupamentos, duas nos homicídios por arma de fogo e uma nas outras formas de homicídio. Em todos os grupos utilizados, e que englobavam mais de um código de causa de morte, foram encontradas discordâncias internas, seja de terceiro ou de quarto dígito. $\mathrm{O}$ percentual global de concordância foi de $81 \%$. A sensibilidade decresceu em quase todas as categorias.

Para o total das causas externas, o percentual global de concordância variou de $94 \%$ para $92 \%$ e, por fim, para $81 \%$, segundo o nível de comparação.

TABELA 3. Distribuição em 14 categorias e concordância entre os dados oficiais e os dados da pesquisa na etapa de codificação da causa básica de morte, Recife (PE), Brasil, 1995a

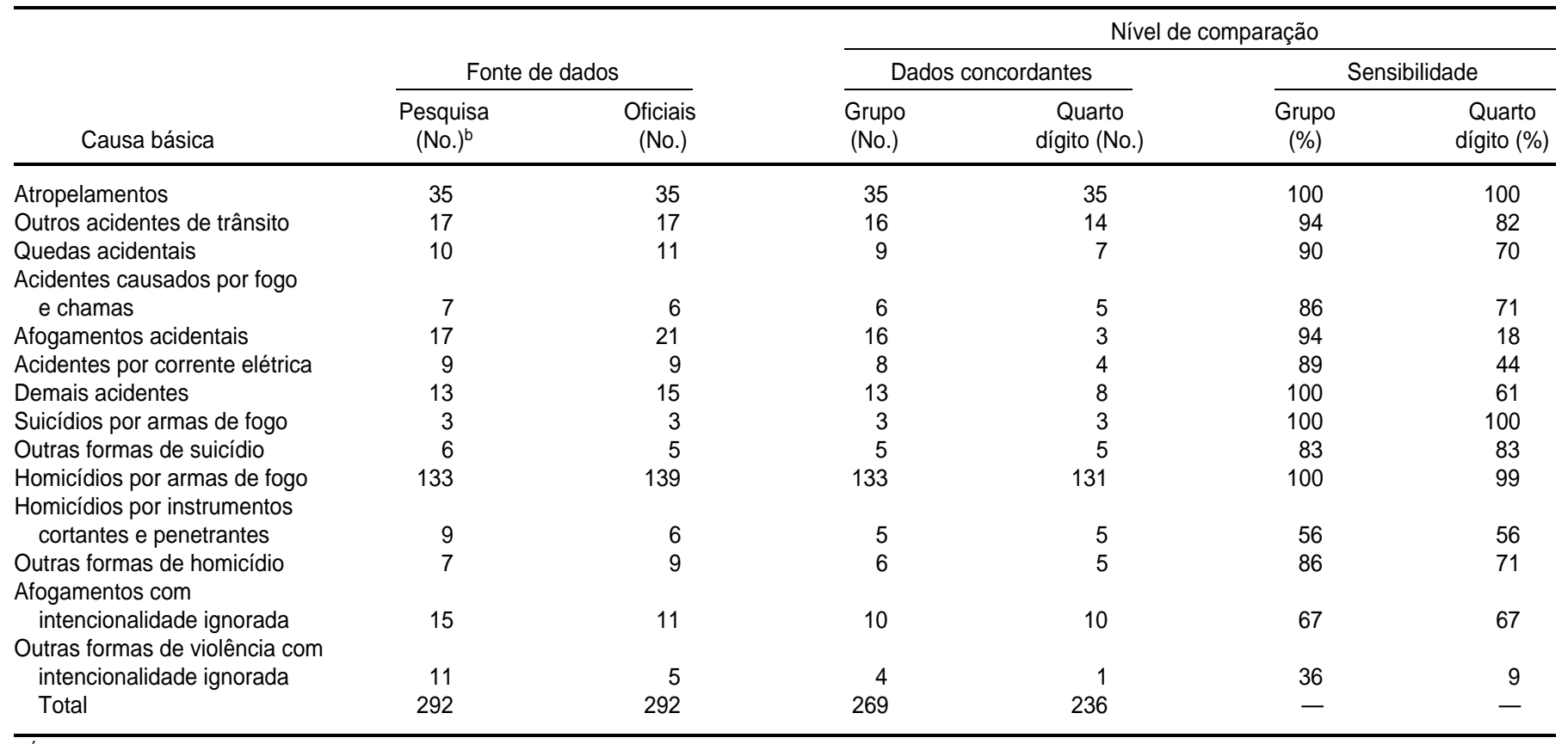

a Óbitos de menores de 20 anos classificados antes da consulta ao Instituto de Medicina Legal, somente com base nas informações disponíveis na Secretaria Municipal de Saúde de Recife. b No. = Número de ocorrências. 
TABELA 4. Comparação das causas básicas dos óbitos por causas externas conforme dados oficiais e dados da pesquisa após investigação no Instituto de Medicina Legal, Recife (PE), Brasil, 1995 a

\begin{tabular}{lcccccr}
\hline & \multicolumn{5}{c}{ Dados oficiais } \\
\cline { 2 - 7 } \multicolumn{1}{c}{$\begin{array}{c}\text { Acidentes } \\
\text { Pesquisa }\end{array}$} & $\begin{array}{c}\text { Outros } \\
\text { trânsito }\end{array}$ & acidentes & Suicídios & Homicídios & $\begin{array}{c}\text { Outras } \\
\text { formas de } \\
\text { violência }\end{array}$ & Total \\
\hline Acidentes & & & & & & \\
$\quad$ de trânsito & 51 & 2 & 0 & 0 & 1 & 54 \\
$\begin{array}{l}\text { Outros acidentes } \\
\text { Suicídios }\end{array}$ & 1 & 47 & 0 & 2 & 5 & 55 \\
$\quad$ Homicídios & 0 & 0 & 8 & 0 & 1 & 9 \\
$\quad \begin{array}{l}\text { Outras formas de } \\
\text { violência }\end{array} \quad 0$ & 0 & 0 & 152 & 0 & 152 \\
$\quad$ Total & 0 & 5 & 0 & 0 & 9 & 14 \\
\hline
\end{tabular}

Fonte: Declarações de óbito/Secretaria Municipal de Saúde do Recife; Instituto de Medicina Legal de Pernambuco, Brasil. a Óbitos de menores de 20 anos.

TABELA 5. Distribuição em cinco categorias e concordância entre os dados oficiais e os dados da pesquisa após a investigação no Instituto de Medicina Legal para classificação da causa básica de morte, Recife (PE), Brasil, 1995ª

\begin{tabular}{lrrrr}
\hline & \multicolumn{3}{c}{ Número de ocorrências } \\
\cline { 2 - 4 } \multicolumn{1}{c}{ Causa básica } & Pesquisa & $\begin{array}{c}\text { Dados } \\
\text { oficiais }\end{array}$ & $\begin{array}{c}\text { Dados } \\
\text { concordantes }\end{array}$ & Sensibilidade (\%) \\
\hline Acidentes de trânsito & 54 & 52 & 51 & 94 \\
Outros acidentes & 55 & 54 & 47 & 85 \\
Suicídios & 9 & 8 & 8 & 89 \\
Homicídios & 152 & 154 & 152 & 100 \\
Outras formas de violência & 14 & 16 & 9 & 64 \\
$\quad$ Total & 284 & 284 & 267 & - \\
\hline
\end{tabular}

Fonte: Secretaria Municipal de Saúde do Recife; Instituto de Medicina Legal de Pernambuco, Brasil.

a Óbitos de menores de 20 anos.

\section{Comparação entre dados oficiais e dados da pesquisa na etapa de validação após investigação no Instituto de Medicina Legal}

Nesta etapa, foram investigados 284 óbitos. No agrupamento das causas básicas em cinco categorias, em relação aos homicídios, chamou a atenção o fato de que todos os casos assim classificados pela pesquisa foram identificados pelos dados oficiais. Por outro lado, dois óbitos considerados como homicídios nos dados oficiais foram codificados pela pesquisa, após investigação, como acidentes (tabela 4). A sensibilidade foi alta nas categorias bem definidas acidentes de trânsito, suicídios e homicídios - e baixa para as outras formas de violência (tabela 5). $\mathrm{O}$ valor do índice kappa de 0,906 (IC95\% = $0,863-0,949$ ) e o percentual global de concordância de $94 \%$ mostraram que as DO apresentaram concordância ótima no agrupamento em cinco categorias.

A distribuição em 14 categorias mostrou grupos heterogêneos, como outras formas de violência com intencionalidade ignorada e demais acidentes. Mesmo categorias bem definidas, como homicídios por instrumentos cortantes e penetrantes, tiveram baixa sensibilidade (tabela 6). O índice kappa calculado para o agrupamento foi de 0,881 (IC95\% = 0,838-0,924) e o percentual global de concordância foi $91 \%$.
Mais uma vez procedeu-se à análise até o quarto dígito, embora os dados tenham sido resumidos em 14 categorias para apresentação em tabela (tabela 6). Essa análise revelou mais 52 discordâncias. Os acidentes de trânsito mostraram 14 divergências, quando o agrupamento em 14 categorias tinha indicado quatro. Uma observação mais detalhada mostrou que sete casos de discordância foram colisões entre veículos a motor e três, outros acidentes sem colisão, classificados como acidente de trânsito sem outra especificação (código E-819 da CID-9). Os dados oficiais registraram como acidente de trânsito sem outra especificação 17 dos 52 óbitos que foram classificados como acidentes de trânsito, enquanto a pesquisa assim registrou sete das 54 mortes codificadas como decorrentes de acidentes de trânsito. As discordâncias na classificação dos óbitos por acidentes outros que não de trânsito ficaram mais evidentes quando da análise até o quarto dígito, chegando a 36 se somadas às discordâncias das cinco categorias em que foram subdivididos. Distribuíram-se por todas as categorias, sendo mais freqüentes para os afogamentos, onde a comparação anterior havia apontado divergências na codificação. Quanto aos homicídios, mais 13 discordâncias foram identificadas em nível de três e quatro dígitos, 10 relativas ao tipo de arma e três quanto ao tipo de envenenamento.

A sensibilidade caiu acentuadamente na maior parte das categorias. $\mathrm{O}$ percentual global de concordância foi de $73 \%$.

Foram 50 as $\mathrm{DO}$ em que os peritos do IML assinalaram o tipo de violência como ignorado, óbitos que seriam, portanto, classificados em outras formas de violência caso a SMS/PCR não complementasse os dados nessas DO. A classificação de causa básica feita pela SMS para essas DO, após essa complementação, foi cotejada com a realizada pela pesquisa, após investigação no IML, tendo sido evidenciadas 13 discordâncias $(26 \%)$. Em termos absolutos, a discordância nesse grupo foi maior do que nos grupos de outros aci- 
TABELA 6. Distribuição em 14 categorias e concordância entre os dados oficiais e os dados da pesquisa após a investigação no Instituto de Medicina Legal para classificação da causa básica de morte, Recife (PE), Brasil, 1995a

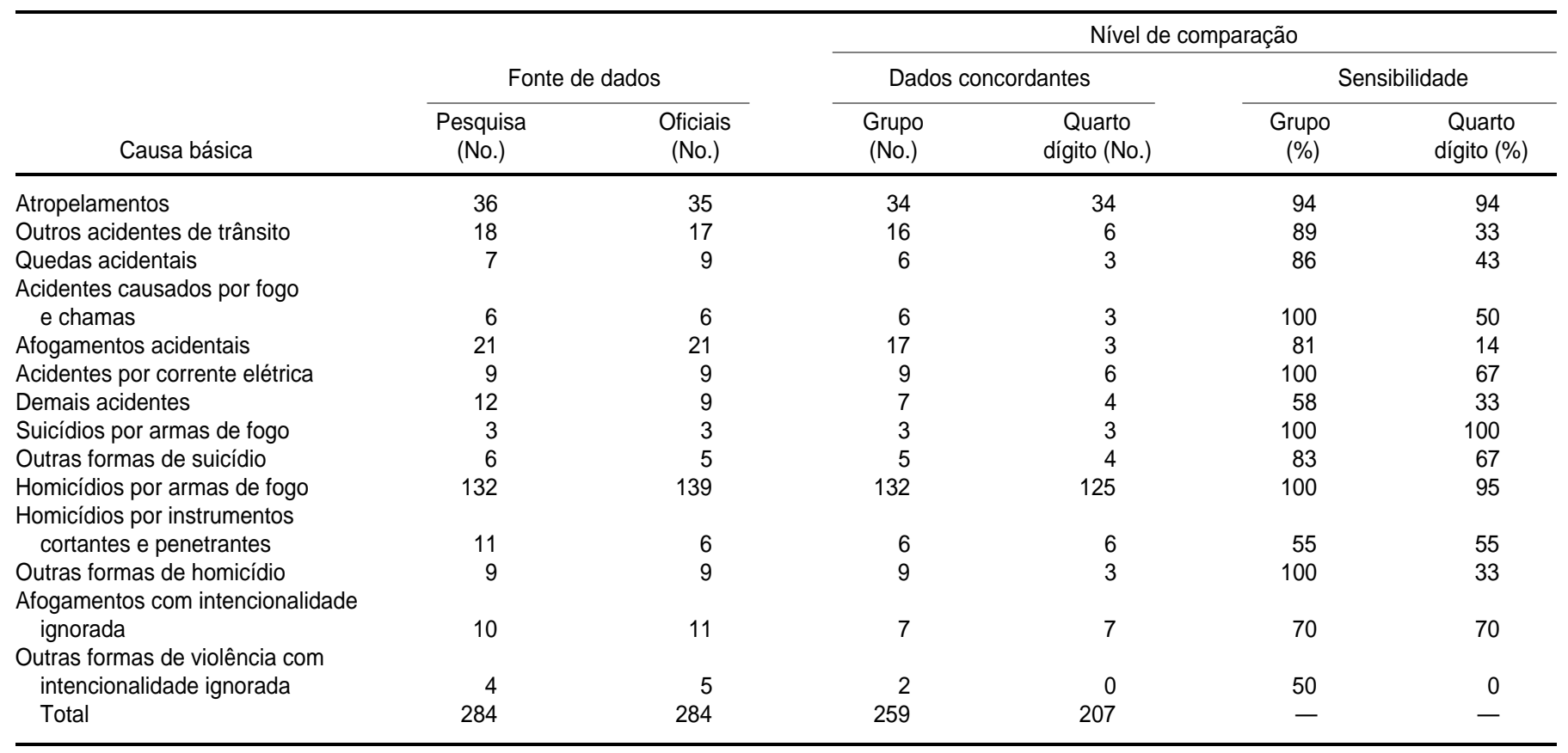

Fonte: Secretaria Municipal de Saúde de Recife; Instituto de Medicina Legal de Pernambuco, Brasil.

a Óbitos de menores de 20 anos.

dentes (cinco casos) e outras formas de violência (cinco casos) (tabela 7). A sensibilidade foi elevada apenas para os homicídios (tabela 8). O percentual de concordância global para o conjunto dos 50 óbitos foi de $74 \%$, e o índice kappa foi 0,631 (IC95\% = 0,453-0,809), ambos bem inferiores aos encontrados quando comparados os dados oficiais e da pesquisa para o total de óbitos do estudo - na etapa de validação, para os 284 óbitos distribuídos em cinco categorias, o percentual global de concordância foi de $94 \%$ e o índice kappa, 0,906 (IC95\% = 0,863-0,949).

Caso não houvesse complementação de dados nas DO com tipo de violência ignorado, dos 284 óbitos do estudo, 50 $(18 \%)$ teriam sido classificados como outras formas de violência.

\section{DISCUSSÃO}

Diversos estudos comparam as causas básicas contidas nas DO com aquelas obtidas de outras fontes, mos-

TABELA 7. Comparação das causas básicas dos óbitos classificadas como tipo de violência ignorado pelos médicos legistas conforme dados oficiais e dados da pesquisa após investigação no Instituto de Medicina Legal, Recife (PE), Brasil 1995a

\begin{tabular}{|c|c|c|c|c|c|c|}
\hline \multirow[b]{2}{*}{ Pesquisa } & \multicolumn{6}{|c|}{ Dados oficiais } \\
\hline & $\begin{array}{c}\text { Acidentes } \\
\text { de } \\
\text { trânsito }\end{array}$ & $\begin{array}{c}\text { Outros } \\
\text { acidentes }\end{array}$ & Suicídios & Homicídios & $\begin{array}{l}\text { Outras } \\
\text { formas de } \\
\text { violência }\end{array}$ & Total \\
\hline \multicolumn{7}{|l|}{ Acidentes } \\
\hline de trânsito & 1 & 1 & 0 & 0 & 1 & 3 \\
\hline Outros acidentes & 0 & 15 & 0 & 0 & 5 & 20 \\
\hline Suicídios & 0 & 0 & 3 & 0 & 1 & 4 \\
\hline Homicídios & 0 & 0 & 0 & 9 & 0 & 9 \\
\hline \multicolumn{7}{|l|}{ Outras formas de } \\
\hline violência & 0 & 5 & 0 & 0 & 9 & 14 \\
\hline Total & 1 & 21 & 3 & 9 & 16 & 50 \\
\hline
\end{tabular}

Fonte: Declarações de óbito/Secretaria Municipal de Saúde de Recife; Instituto de Medicina Legal de Pernambuco, Brasil. a Óbitos de menores de 20 anos.

trando graus variáveis de discordância, tanto no Brasil $(8,9,17,19)$ como em outros países $(2,3)$.

Em Recife, a SMS/PCR vem fazendo complementação de dados nas DO com tipo de violência ignorado, mas não se encontrou avaliação desse processo, a não ser em termos da diminuição percentual da categoria "outras formas de violência". Também não há registro de nenhum trabalho de validação, seja de causa básica de morte, seja de outras variáveis, nas DO por causas externas para o Município de Recife; tais constatações justificam a realização do presente estudo. 
TABELA 8. Distribuição em cinco categorias e concordância entre os dados oficiais e os dados da pesquisa após a investigação no Instituto de Medicina Legal para classificação da causa básica de morte, Recife (PE), Brasil, 1995

\begin{tabular}{lcccc}
\hline & \multicolumn{4}{c}{ Número de ocorrências } \\
\cline { 2 - 5 } \multicolumn{1}{c}{ Causa básica } & Pesquisa & $\begin{array}{l}\text { Dados } \\
\text { oficiais }\end{array}$ & $\begin{array}{c}\text { Dados } \\
\text { concordantes }\end{array}$ & Sensibilidade (\%) \\
\hline Acidentes de trânsito & 3 & 1 & 1 & 33 \\
Outros acidentes & 20 & 21 & 15 & 75 \\
Suicídios & 4 & 3 & 3 & 75 \\
Homicídios & 9 & 9 & 9 & 100 \\
Outras formas de & 14 & 16 & 9 & 64 \\
$\quad$ violência & 50 & 50 & 37 & - \\
$\quad$ Total & 50 & &
\end{tabular}

Fonte: Declarações de óbitos/Secretaria Municipal de Saúde de Recife; Instituto de Medicina Legal de Pernambuco, Brasil. a Óbitos de menores de 20 anos.

\section{Comparação entre dados oficiais e dados da pesquisa na etapa de codificação}

A sensibilidade relativamente baixa encontrada nesta etapa de comparação para a categoria de óbitos em que não se determina a intencionalidade é produto não só do inadequado preenchimento das DO, mas também da interpretação dos codificadores quanto à classificação das causas básicas. Observou-se que, em 26 situações, o perito padrão da pesquisa considerou insuficientes os dados constantes nas DO para classificação da causa básica (a não ser na categoria de outras formas de violência), enquanto os codificadores da SMS classificaram na categoria de outras formas de violência apenas 16 casos. A explicação sugerida para essa divergência é a de que os objetivos de um e outro codificador nessa fase do trabalho foram diferentes. Enquanto o perito padrão da pesquisa sabia que aquele era um momento inicial e que, posteriormente, todos aqueles óbitos seriam investigados, para os codificadores do serviço de saúde era o momento de decidir entre manter aqueles óbitos como de tipo de violência ignorado ou enquadrá-los em outros grupos.

As comparações por agrupamentos podem mascarar diferenças de causa básica (8). Ainda, quanto mais abrangentes os grupos, mais podem ocultar discordâncias, aumentando, por con- seguinte, o grau de concordância (26). Os valores do índice kappa para os agrupamentos de cinco categorias principais e 14 secundárias neste estudo corroboram essas tendências.

\section{Comparação entre dados oficiais e dados da pesquisa na etapa de validação após investigação no Instituto de Medicina Legal}

Vários estudos têm comparado as causas básicas constantes nos dados oficiais com as obtidas de outras fontes. Em alguns desses trabalhos, a própria equipe que fez a investigação foi responsável pela codificação das causas básicas identificadas $(2,8,9,16$, 17). Outros autores definiram, em sua metodologia, que os atestados feitos pelos pesquisadores seriam codificados pelo mesmo grupo responsável pela codificação dos dados oficiais (5, 19). Sabe-se que os dois aspectos podem interferir nessa comparação: diferenças decorrentes do processo de codificação e diferenças devidas às fontes de dados. No entanto, esses estudos têm enfatizado o maior detalhamento que se pode atingir na definição da causa básica quando da investigação em outras fontes de dados, não tendo quantificado ou discutido possíveis divergências por conta da diferença de codificadores $(2,8,16,17)$. No presente trabalho, as causas básicas, produto da investigação no IML pelo perito padrão da pesquisa, foram por ele codificadas; por conseguinte, como no primeiro bloco de estudos citados $(2,8,9,16,17)$, foram comparados os resultados obtidos com instrumentos e codificadores diferentes e, conseqüentemente, os dois tipos de diferenças se somaram.

A análise em 14 categorias secundárias evidenciou a queda de sensibilidade em determinados grupos em relação à análise em cinco categorias principais, como no caso dos homicídios por instrumentos cortantes e penetrantes. Porém, foi a análise até o quarto dígito, com a investigação de todos os óbitos no IML, que revelou o maior detalhamento que pode ser atingido, mesmo dentro dos grupos mais definidos.

Todavia, é ainda importante o número de óbitos classificados em categorias inespecíficas. Os óbitos por acidentes de trânsito que permaneceram, mesmo após a investigação, classificados em E-819, foram encaminhados ao IML por hospitais e acompanhados por guias de remoção de cadáveres, que são preenchidas nos hospitais e delegacias quando do encaminhamento do cadáver ao IML. Pela pobreza do preenchimento, as guias não permitiram uma melhor classificação. Como nesta pesquisa, outros autores (16) encontraram baixa concordância para as causas básicas em óbitos hospitalares por acidentes de trânsito quando compararam as informações das DO com as obtidas pela pesquisa nos prontuários. Tal fato sugere que os dados das fichas hospitalares, que poderiam ajudar na determinação da causa básica, não são repassados às guias de remoção de cadáveres de forma satisfatória.

Nos acidentes de trânsito, o quarto dígito destina-se a determinar a pessoa traumatizada (condutor, passageiro, pedestre, ciclista, pessoa não especificada, etc.), mas, exceto para os atropelamentos, geralmente consta nas DO o digito 9 , correspondente a pessoa não especificada $(2,16)$. Em anos recentes, a inclusão na DO da variável tipo de acidente vem revelando muitos atropelamentos, antes freqüentemente en- 
cobertos e classificados como acidentes de trânsito sem outra especificação, tendo em vista que atropelamento constitui-se em uma das opções a ser assinalada naquela variável.

As categorias em que foram divididos os outros acidentes tiveram importantes decréscimos na sua concordância por conta do maior detalhamento que pode ser alcançado quando da investigação no IML. Contudo, números importantes de óbitos permaneceram classificados, em nível do quarto dígito, em categorias sem outra especificação (afogamentos, quedas, acidentes por fogo e chamas e acidentes por corrente elétrica), mesmo nos dados da pesquisa após investigação naquele Instituto. Esse fato reforça a observação de que mesmo a revisão de todas as DO no IML não permite um conhecimento tão amplo da causa básica, devido à pobreza do preenchimento, nos hospitais e delegacias, das guias de encaminhamento dos cadáveres.

Depreende-se, portanto, que os investimentos para melhoria dos dados de mortalidade por causas externas precisam ir além do IML. Assim sendo, torna-se essencial que as guias de encaminhamento de hospitais ou delegacias contenham os dados necessários para um completo preenchimento das variáveis da DO como um todo e, em particular, da ocorrência do evento que conduziu ao óbito.

Quanto aos homicídios, a observação até o quarto dígito mostrou que a grande maioria permaneceu enquadrada no código E-965.4, correspondente a homicídios por outras armas de fogo e causas não especificadas. Esse achado evidencia que os dados das guias de remoção de cadáveres de hospitais e delegacias não permitem um maior detalhamento desse grupo. Autores nos Estados Unidos também referiram a baixa sensibilidade das DO para a definição do quarto dígito nas causas externas (2).

O IML, não assumindo como de sua responsabilidade indicar como causa básica a circunstância do acidente ou lesão que levou diretamente ao óbito $(12,30)$, induz a que os serviços de saúde façam suas próprias leituras. Assim, ferimentos produzidos por instrumentos perfurocontundentes são, em geral, classificados como por arma de fogo, porém isso nem sempre é verdadeiro. A observação feita pretende chamar atenção para o fato de que uma maior fidelidade dos dados de causa básica seria possível com o IML assumindo a determinação da causa básica como definida na CID-9 (21).

Em anos recentes, foi introduzida nas DO a observação de que os dados da parte VI, que se referem às prováveis circunstâncias da morte nos casos de morte não natural, são de caráter epidemiológico. Foi também incorporado um item onde o perito esclareceria a fonte de informação do tipo de causa externa ou tipo de acidente anotado. Não se encontrou registro da data exata dessa introdução, nem do processo que a normatizou, bem como não foram encontrados trabalhos avaliando o seu impacto. Nossos dados sugerem que não houve modificação na conduta dos peritos do IML em Recife, pelo menos no que se refere aos óbitos por causas externas de menores de 20 anos registrados em 1995. Se a incorporação daquela observação foi discutida entre os setores envolvidos - saúde e segurança pública - tornase difícil entender a resistência por parte do IML à adoção dessa estratégia. Por outro lado, se ela ocorreu por decisão isolada do setor saúde, a probabilidade de sucesso não parece tangível. Na lógica de produção da informação, o aspecto da exeqüibilidade precisa ser também considerado (31).

Neste estudo, como já foi enfatizado, foram os óbitos que o IML assinalou com tipo de violência ignorado que geraram as maiores discordâncias na comparação dos dados, inclusive divergências em termos de grupos específicos de causas. Considerando que o serviço de saúde e a pesquisa utilizaram a mesma fonte para busca dos dados, as diferenças foram provavelmente motivadas pelo modo de investigação, instrumentos consultados e priorizados e também pelas diferenças de codificação que se somaram nessa etapa de comparação.
Os serviços e pesquisadores, quando das investigações nos IML, aliam a informação registrada nos laudos de perícia tanatoscópica com os dados das guias de encaminhamento para tentar definir a causa básica dos óbitos com tipo de violência ignorado. $\mathrm{Na}$ revisão da literatura, bem como no desenvolvimento da pesquisa, não se encontrou normatização para o processo de complementação de dados, seja para o município, seja para o estado. Assim, não há uma padronização formal dos critérios adotados. Conseqüentemente, tornamse mais prováveis as mudanças segundo a equipe de codificação ou com a passagem do tempo, e isso ficou retratado na fragilidade da DO nesse item específico ao analisar a sua repetibilidade.

Se os peritos médico-legais, que têm maiores condições para definir a provável causa de morte, não o fazem, duas alternativas se colocam: outros com menor treinamento e menor acesso a todos os documentos dos casos passam a assumir essa função; ou são mantidos os altos percentuais de óbitos por causas externas classificados como resultantes de lesões das quais se ignora se foram acidental ou intencionalmente infligidas.

Este estudo identificou as DO definidas como de tipo de violência ignorado para o IML, e verificou como haviam sido reclassificadas pela SMS e pela pesquisa após investigação. Os dados encontrados reforçaram a observação de que a confiabilidade do próprio instrumento fica prejudicada quando sai do IML com tipo de violência ignorado (28). Assim, mesmo considerando apenas o agrupamento em cinco categorias, o índice kappa foi muito inferior ao encontrado para o total dos óbitos do estudo.

A distribuição da mortalidade por grupos específicos de causas externas com complementação de dados no IML pelo serviço de saúde sofreu importantes alterações em 1995. Os grupos de outras formas de violência e outros acidentes quase inverteram seus posicionamentos. Esse achado foi concordante com as observações de 
outros autores $(32,33)$. Importante também o baixo número registrado de mação desse tipo de causa de morte $(7,14)$. Chamou atenção o elevado percentual de afogamentos cuja intencionalidade não foi especificada pelos peritos do IML. Seria importante o aprofundamento desse ponto junto ao IML, discutindo as dificuldades para definição do tipo de violência nessa categoria de causa de morte em particular e as possibilidades de contornásuicídios, que corrobora as colocações de alguns autores sobre a subesti-

las. Não só os dados deste trabalho, mas também a revisão da literatura, sugerem que a forma de complementação dos dados através de investigação por parte dos serviços de saúde é importante, mas deve ser vista como uma etapa transitória, sendo a definitiva o preenchimento das DO pelo IML segundo as normas e dentro dos padrões adequados. Fica entendido que, para isso, aquele serviço precisaria receber guias de remoção de cadáveres corretamente preenchidas pelos hospitais e delegacias.

\section{REFERÊNCIAS}

1. Kircher T, Anderson RE. Cause of death proper completion of the death certificate. JAMA 1987;258(3):349-352.

2. Moyer LA, Boyle CA, Pollock DA. Validity of death certificates for injury-related causes of death. Am J Epidemiol 1989; 130(5):1024-1032.

3. Kircher T. The autopsy and vital statistics. Hum Pathol 1990; 21(2):166-173.

4. Rachuba L, Stanton B, Howard D. Violent crime in the United States: an epidemiologic profile. Arch Pediatr Adolesc Med 1995; 149(9):953-960.

5. Messite J, Stelman SD. Accuracy of death certificate completion. JAMA 1996;275(10): 795-796.

6. Hanzlick R. Death registration: history, methods, and legal issues. J Forensic Sci 1997;2(2): 265-269.

7. Szwarcwald CL, Castilho EA. Mortalidade por causas externas no estado do Rio de Janeiro no período de 1976 a 1980. Cadernos Saude Publica 1986;2(1):19-41.

8. Mello Jorge MHP. Situação atual das estatísticas oficiais relativas à mortalidade por causas externas. Rev Saude Publica 1990;24(3): 217-223.

9. Souza ER. Violência velada e revelada: estudo epidemiológico da mortalidade por causas externas em Duque de Caxias - Rio de Janeiro [dissertação]. Rio de Janeiro: Escola Nacional de Saúde Pública/FIOCRUZ; 1991.

10. Laurenti R, Mello Jorge MHP. O atestado de óbito. São Paulo: Centro Brasileiro da OMS para Classificações de Doenças em Português; 1993.

11. Camargo ABM, Ortiz LP, Fonseca LAM. Evolução da mortalidade por acidentes e violência em áreas metropolitanas. Em: Monteiro CA, ed. Velhos e novos males da saúde no Brasil. São Paulo: HUCITEC/NUPENS/USP, 1995. p. 257-267.

12. Souza ER, Njaine K, Minayo MCS. Qualidade da informação sobre violência: um caminho para a construção da cidadania. Cad Prog Pos-Grad Cienc Inf 1996;2(1):104-112.

13. Oliveira H, Pereira IPA. Estatísticas de mortalidade e nascidos vivos: considerações sobre principais problemas. Inf Epidemiol SUS 1997;3:15-19.

14. Mello Jorge MHP, Gawryszewski VP, Latorre MRDO. Análise dos dados de mortalidade. Rev Saude Publica 1997;31 Supl 4:5-25.

15. Souza ER, Assis SG, Silva CMFP. Violência no município do Rio de Janeiro: áreas de risco e tendências da mortalidade entre adolescentes de 10 a 19 anos. Rev Panam de Salud Publica 1997; 1(5):389-395.

16. Ladeira RM, Guimarães MD. Análise da concordância da codificação de causa básica de óbito por acidentes de trânsito. Rev Saude Pur blica 1998; 32(2):133-137.

17. Nobre LC, Victora CG, Barros FC. Avaliação da qualidade da informação sobre a causa básica de óbitos infantis no Rio Grande do Sul. Rev Saude Publica 1989;23(3):207-213.

18. Niobey FML, Cascão AM, Duchiade MP. Qualidade do preenchimento de atestado de óbitos de menores de um ano na região metropolitana do Rio de Janeiro. Rev Saude Publica 1990; 24(4):311-318.

19. Mendonça EF, Goulart EMA, Machado JAD. Confiabilidade da declaração de causa básica de mortes infantis em região metropolitana do Sudeste do Brasil. Rev Saude Publica 1994; 28(5):385-391.

20. Njaine K, Souza ER, Minayo MCS, Assis SG. A produção da des(informação) sobre violência: análise de uma prática discriminatória. Cad Saude Publica 1997;13(3):405-414.

21. Organização Mundial da Saúde (OMS). Manual da Classificação Estatística Internacional de Doenças, Lesões e Causas de Óbito - 9a revisão. São Paulo: Centro da OMS para Classificação das Doenças em Português; 1985.

22. Paula AMC, Filho DE, Pereira IPA, Albano AHBL. Avaliação dos dados de mortalidade, Brasil — 1979 a 1989. Inf Epidemiol SUS 1994; 1:21-41.

23. Guimarães MJB, Lessa F, Regazzi AP, Aquino T, Melo N. Violência urbana em Recife: ascensão da mortalidade por causas externas 1980- 1991. Em: Resumos do $1^{\circ}$ Congresso Brasileiro de Ciências Sociais em Saúde; 7-10
Em síntese, a análise do SIM em Recife mostrou que dados mais fidedignos podem ser produzidos, permitindo, portanto, que se faça um melhor delineamento do padrão de mortalidade por causas externas. Ressalta-se que é fundamental não só gerar, mas divulgar dados mais precisos, para que a sociedade conheça melhor o seu padrão de violência; e, sobretudo, é fundamental que esses dados sejam usados, especialmente para promover intervenções de controle de mortes por causas externas. nov 1995; Curitiba, Paraná. Curitiba: ABRASCO; 1995. p. 53.

24. Lessa F, Guimarães MJB, Santos S, Parente S, Antunes A, Avelar I. Um retrato da violência em Recife em 1994. Em: Resumos do $1^{\circ}$ Congresso Brasileiro de Ciências Sociais em Saúde; 7-10 nov 1995; Curitiba, Paraná Curitiba: ABRASCO; 1995. p. 133.

25. Antunes MBC, Gentile AR, Soares JRR, Guimarães MJB. Causas externas uma realidade mal definida: análise de uma rotina em serviço no resgate das informações. Em: Resumos do $4^{\circ}$ Congresso Brasileiro de Saúde Coletiva;19-23 Jun 1994; Recife, Pernambuco. Recife: ABRASCO; 1994. p. 7.

26. Altman DG. Practical statistics for medical research. London: Chapman \& Hall; 1995.

27. Fleiss JL. Statistical methods for rates and proportions. New York: John Wiley; 1981.

28. Almeida Filho N, Rouquayrol MZ. Introdução à epidemiologia moderna. Rio de Janeiro: ABRASCO; 1990.

29. Andrade ALS, Zicker F, org. Métodos de investigação epidemiológica em doenças transmissíveis. Brasília: OPS/MS/CENEPI; 1997.

30. Laurenti R, Mello Jorge MHP, Lebrão ML, Gotlieb SLD. Estatísticas de saúde. 2a ed. São Paulo: EPU; 1987.

31. Branco MAF. Sistemas de informação em saúde no nível local. Cad Saude Publica 1996;12(2):267-270.

32. Barros MDA. A mortalidade por causas externas em crianças e adolescentes residentes no Recife: análise de tendência na série temporal de 1979 a 1995 e uma avaliação do sistema de informação [dissertação]. Recife: Instituto Materno-Infantil de Pernambuco; 1999.

33. Menezes Filho A, Cavalcanti AMS, Jurandir D. Mortalidade por causas externas: uma das faces da violência urbana, Recife, 1971-1985 [monografia]. Recife: Núcleo de Estudos de Saúde Coletiva, CPqAM/FIOCRUZ; 1989.

Manuscrito recebido em 22 de março de 2000. Aceito em versão revisada em 16 de novembro de 2000. 
ABSTRACT Objective. To validate the underlying cause of death recorded on the death certificates for individuals under 20 years of age who died from external causes in 1995 in Recife, Pernambuco, Brazil.

\title{
Underlying cause of death from external causes: validation of official data in Recife, Pernambuco, Brazil
}

Methods. We divided the study into two stages, coding and validation. In both stages we compared the official data concerning causes of death to the data we obtained during our study. We grouped the death certificates into 5 broad categories according to the cause of death; we later subdivided them into 14 categories. We also individually compared the death certificates applying the four-digit system of the International Classification of Diseases, Ninth Revision (ICD-9). We assessed the agreement between the official data and our data in terms of sensitivity and the kappa coefficient. We took as the standard the categorization of the cause of death that we had made during our investigation.

Results. In the coding stage, considering all the external causes of death, the overall agreement between the official data and our study data was $94 \%$ for the 5 categories, $92 \%$ for the 14 categories, and $81 \%$ for the four-digit ICD-9 system. In the validation stage the overall agreement was $94 \%$ for the 5 categories, $91 \%$ for the 14 categories, and $73 \%$ for the four-digit ICD-9 system.

Conclusions. Our results suggest that for the death certificates to be reliable, the Institute of Legal Medicine must fill them out following recommended standards. In addition, hospitals and police departments must use greater care in completing the transfer slips that accompany the bodies that are sent to the Institute. More accurate data need to be generated and disseminated for a society to better understand its patterns of violence.

\section{Curso Hispano-Argentino de Micología Médica Determinación de la Resistencia a los Antifúngicos en el Laboratorio}

Fecha: 6 a 10 de agosto de 2001
Lugar: Buenos Aires, Argentina

Este curso, que tiene el financiamiento parcial de la Organización Panamericana de la Salud y que ha sido organizado en conjunto por la Unidad de Micología del Instituto Carlos III de España y el Departamento de Micología del Instituto Nacional de Enfermedades Infecciosas (INE) de la Administración Nacional de Laboratorios e Institutos de Salud "Dr. Carlos G Malbrán" (ANLIS), tiene una duración de 40 horas, después de las cuales habrá una evaluación final. Los siguientes son ejemplos de algunos de los temas que serán debatidos: los métodos de referencia de NOCLS; Ios métodos espectrofotométrico, colorimétrico y por difusión para la determinación de sensibilidad; la utilidad de las pruebas de sensibilidad a los antifúngicos, y la correlación entre estas y la evolución clínica del paciente.

\author{
Información: \\ Departamento de Micología \\ INE.ANLIS “Dr. Carlos G Malbrán” \\ Av. Vélez Sarsfield 563 \\ Buenos Aires (1281), Argentina \\ Tel./fax: 54-11-4302-5066 \\ Correo electrónico: Irodero@mail.retina.ar
}

